BMJ Open Diabetes Research \& Care

\title{
Development of a prediction model for foot ulcer recurrence in people with diabetes using easy-to-obtain clinical variables
}

\author{
Wouter B aan de Stegge (D) ,1,2 Martijn C Schut,, Ameen Abu-Hanna, ${ }^{3}$ \\ Jeff $\mathrm{G}$ van Baal, ${ }^{2}$ Jaap J van Netten (D) , ${ }^{1}$ Sicco A Bus (D) ${ }^{1}$
}

To cite: aan de Stegge WB, Schut MC, Abu-Hanna A, et al. Development of a prediction model for foot ulcer recurrence in people with diabetes using easyto-obtain clinical variables. BMJ Open Diab Res Care 2021;9:e002257. doi:10.1136/ bmjdrc-2021-002257

- Supplemental material is published online only. To view, please visit the journal online (http://dx.doi.org/10.1136/ bmjdrc-2021-002257).

Received 8 March 2021 Accepted 30 June 2021

Check for updates

(c) Author(s) (or their employer(s)) 2021. Re-use permitted under CC BY-NC. No commercial re-use. See rights and permissions. Published by BMJ.

${ }^{1}$ Amsterdam UMC, Department of Rehabilitation Medicine, University of Amsterdam, Amsterdam Movement Sciences, Amsterdam, The Netherlands

${ }^{2}$ Hospital Group Twente, Department of Surgery, Almelo, The Netherlands

${ }^{3}$ Amsterdam UMC, Department of Medical Informatics, University of Amsterdam, Amsterdam, The Netherlands

Correspondence to Dr Sicco A Bus; s.a.bus@amsterdamumc.nl

\section{ABSTRACT}

Introduction We aimed to develop a prediction model for foot ulcer recurrence in people with diabetes using easyto-obtain clinical variables and to validate its predictive performance in order to help risk assessment in this highrisk group.

Research design and methods We used data from a prospective analysis of 304 people with foot ulcer history who had 18-month follow-up for ulcer outcome. Demographic, disease-related and organization-of-care variables were included as potential predictors. Two logistic regression prediction models were created: model 1 for all recurrent foot ulcers ( $n=126$ events) and model 2 for recurrent plantar foot ulcers ( $n=70$ events). We used 10-fold cross-validation, each including five multiple imputation sets for internal validation. Performance was assessed in terms of discrimination using area under the receiver operating characteristic curve (AUC) $(0-1$, $1=$ perfect discrimination), and calibration with the Brier Score $(0-1,0=$ complete concordance predicted vs observed values) and calibration graphs.

Results Predictors in model 1 were: a younger age, more severe peripheral sensory neuropathy, fewer months since healing of previous ulcer, presence of a minor lesion, use of a walking aid and not monitoring foot temperatures at home. Mean AUC for model 1 was 0.69 (2SD 0.040) and mean Brier Score was 0.22 (2SD 0.011). Predictors in model 2 were: a younger age, plantar location of previous ulcer, fewer months since healing of previous ulcer, presence of a minor lesion, consumption of alcohol, use of a walking aid, and foot care received in a university medical center. Mean AUC for model 2 was 0.66 (2SD 0.023 ) and mean Brier Score was 0.16 (2SD 0.0048). Conclusions These internally validated prediction models predict with reasonable to good calibration and fair discrimination who is at highest risk of ulcer recurrence. The people at highest risk should be monitored more carefully and treated more intensively than others. Trial registration number NTR5403.

\section{INTRODUCTION}

A foot ulcer is a feared and common complication in people with diabetes mellitus. The presence of a foot ulcer has a major impact on an individual's quality of life and places

\section{Significance of this study}

What is already known about this subject?

- People with diabetes, neuropathy and foot ulcer history are in all ulcer risk classification systems stratified as those at highest risk; however, disease severity and ulcer risk vary substantially within this stratum. To provide appropriate preventative treatment and adequately allocate limited recourses, further differentiation for ulcer risk using easy-toobtain clinical variables in this stratum is necessary.

What are the new findings?

- Predictors for foot ulcer recurrence were: a younger age, more severe peripheral sensory neuropathy, fewer months since healing of the previous ulcer, presence of a minor lesion, use of a walking aid and not monitoring foot temperature at home.

- Predictors for plantar foot ulcer recurrence were: a younger age, plantar location of the previous ulcer, fewer months since healing of the previous ulcer, presence of a minor lesion, consumption of alcohol, use of a walking aid, and foot care received in a university medical center.

- All predictors found can be easily obtained by healthcare professionals when screening people with diabetes and foot ulcer history.

How might these results change the focus of research or clinical practice?

- Clinical practice may use these prediction models to better determine which high-risk people with diabetes should be monitored more carefully and treated more intensively.

a large burden on both healthcare systems and society. ${ }^{1-3}$ The annual incidence of a foot ulcer in people with diabetes is approximately $2 \%,{ }^{4}$ while recently the global prevalence was estimated at 18.6 million ( $4.8 \%$ of all people with diabetes). ${ }^{5}$ Approximately $40 \%$ of the patients who heal from an ulcer develop another one within the first 12 months, and $60 \%$ within 3 years. ${ }^{6}$ Because of the high 
incidence of recurrence and subsequent risk of infection, hospital admission and amputation, ${ }^{7}$ prevention of ulcer recurrence is paramount.

In (inter)national guidelines and in current clinical practice, treatment to help prevent a foot ulcer starts with the determination of someone's risk of developing one. ${ }^{8-10}$ Various systems have been developed and validated to stratify people with diabetes according to their risk for ulceration. ${ }^{11-13}$ Guidelines, such as those from the American Diabetes Association, ${ }^{9}$ or the International Working Group on the Diabetic Foot (IWGDF),${ }^{10}$ recommend that people should be screened more frequently when their risk for ulceration increases. In all systems, people with neuropathy and a foot ulcer history are stratified as those at highest risk. However, within this risk group, disease severity and ulcer risk vary substantially. ${ }^{14-19}$ To provide appropriate preventative treatment strategies and to adequately allocate limited recourses, it is important to further differentiate for foot ulcer risk within those people in the highest risk stratum.

Risk factor models can be used for this purpose. Armstrong and colleagues reviewed studies reporting risk factor models for ulcer recurrence ${ }^{6}$ and found a vibration perception threshold $>25 \mathrm{~V},{ }^{20}$ a minor lesion, ${ }^{15}$ a previous ulcer at the plantar foot surface, ${ }^{1421}$ and peripheral artery disease ${ }^{14}$ to be the most important independent risk factors. However, the risk models used in these studies are incomplete and inconsistent in description and interpretation and often lack validation. Also, these studies aimed to explain whether foot ulcer recurrence can reliably be attributed to a risk factor, after adjusting for confounders, in a multivariate analysis, that is, a search for causality. In contrast, prediction models use multiple variables to predict, as accurately as possible, the risk of a future outcome, regardless of causality. ${ }^{22}$ All causal factors are predictors, but not every predictor is a cause. Therefore, more and often easier to obtain variables can be considered in a prediction model than an etiological (causal) model, making prediction models more suitable in daily practice to timely identify people at high risk of ulcer recurrence.

Crawford and colleagues were the first to develop and externally validated a prediction model for people with diabetes at low to high risk of ulceration, and identified as predictors a history of ulceration, inability to feel a $10 \mathrm{~g}$ monofilament and absence of at least one pedal pulse. ${ }^{23}$ These are easy-to-obtain variables in every clinical setting, which facilitates implementation. However, this model does not distinguish between the ulcer risk of people who are stratified as high risk (IWGDF grade 3). The only prediction model developed for high-risk people is our own, on data from 171 people with a recently healed plantar foot ulcer who participated in a trial on efficacy of custom-made footwear. ${ }^{24}$ This model included quantitative biomechanical parameters that are not available in every clinical setting. Furthermore, this model focused on plantar foot ulcer recurrence only, while at least half of all foot ulcers develop at other anatomical locations. ${ }^{7}$
It also used a selected group of high-risk people who all wore custom-made footwear and had their previous foot ulcer healed within 18 months of study entry, limiting its generalizability and implementation. We therefore aimed to develop a prediction model for foot ulcer recurrence using a variety of more easy-to-obtain clinical variables in a diverse group of high-risk people with diabetes (all IWGDF risk 3), and to validate its predictive performance, so to help risk assessment and preventative treatment in this high-risk group.

\section{METHODS}

\section{Population}

We used data from a multicenter randomized controlled trial (RCT) on the effectiveness of at-home monitoring of foot temperatures to prevent foot ulcer recurrence in diabetes. ${ }^{25}$ In this trial, we recruited participants between 2015 and 2018 from multidisciplinary outpatient diabetic foot clinics of three university medical centers and four community hospitals, and several affiliated professional podiatry practices, all from various regions across the Netherlands. The participants received their primary foot care in the centers where they were recruited. From a total of 1411 people screened for eligibility, 304 participants with diabetes, loss of protective sensation (LOPS) and a history of foot ulceration ( $<48$ months prior to enrollment) or a history of Charcot neuroosteoarthropathy were included in this study. LOPS was assessed using a $10 \mathrm{~g}$ Semmes-Weinstein monofilament and a $128 \mathrm{~Hz}$ tuning fork. ${ }^{10}$ We defined a Charcot neuroosteoarthropathy as a non-infectious destruction of bone and joint(s) associated with neuropathy, in the acute (active) phase associated with signs of inflammation such as edema, erythema and skin temperature changes. ${ }^{26} 27$ After consolidation and in the absence of clinical signs the episode of active Charcot neuro-osteoarthropathy was considered to be resolved. ${ }^{26}{ }^{27}$ We excluded individuals if they had a foot ulcer, a foot infection, an active Charcot neuro-osteoarthropathy, chronic limb-threatening ischemia (ie, grade 3 Perfusion Extent Depth Infection Sensation (PEDIS) classification), ${ }^{28}$ bilateral amputation proximal to the tarsometatarsal (Lisfranc) joint, an estimated survival less than 18 months, or if they already used at-home foot temperature monitoring. Participants were randomly assigned to usual care or enhanced care that in addition to usual care included at-home daily measurement of foot temperature at six to eight predefined locations on the foot using infrared thermometry. ${ }^{25}$ Follow-up time was 18 months. This study was registered on the Netherlands Trial Register.

\section{Primary outcome}

The primary outcome was foot ulcer recurrence during the 18 months of follow-up. A foot ulcer was defined as a full-thickness lesion of the skin of the foot, irrespective of duration. ${ }^{27}$ If the participant or treating healthcare professional identified an ulcer during follow-up, 
the professional was instructed to complete a foot ulcer form, take photographs of the ulcer, and send all materials to the study team. During three monthly follow-up calls, participants were asked about any lesion that had occurred, and we checked the electronic patient files for any unreported ulcer. Three independent diabetic foot experts assessed ulcer forms and photographs to determine the ulcer outcome. If not unanimous, two other experts were consulted and a majority vote determined the outcome.

\section{Potential predictors}

We included demographic, disease-related, and organization-of-care variables as potential predictors of foot ulcer recurrence. These potential predictors were collected at baseline through anamnesis, physical examination or questionnaires, and are listed in table 1 .

We classified the consumption of alcohol as none versus $\geq 1$ unit/week and employment as none versus any (retirement was considered as unemployed). If participants were treated by a nephrologist or ophthalmologist, they were considered to have diabetic nephropathy or diabetic retinopathy, respectively. Peripheral neuropathy was assessed by measuring the LOPS by using the $10 \mathrm{~g}$ (5.07) Semmes-Weinstein monofilament at the plantar surface of the hallux and the first and fifth metatarsal heads of both feet. ${ }^{10}$ LOPS was present when the monofilament was not felt on two or more locations. If the monofilament was felt on two or more locations, a $128 \mathrm{~Hz}$ tuning fork was used to assess loss of vibratory sensation. The tuning fork was held on the apex of the great toe and loss of vibratory sensation was present when the participant indicated not to feel the vibration. ${ }^{10}$ We defined severity of peripheral neuropathy as mild when participants were able to sense the $10 \mathrm{~g}$ monofilament, but not the $128 \mathrm{~Hz}$ tuning fork, and as severe when they were unable to sense both. Peripheral artery disease was defined as grade 1 or $2 .^{28}$ We classified foot deformity as absent, mild, moderate or severe. ${ }^{1529}$ A minor lesion was defined as a non-ulcerative lesion of the skin on the foot, that is, abundant callus, hemorrhage, or blister. ${ }^{15}$

We asked participants seven questions regarding their self-care behavior in ulcer prevention (eg, 'do you walk barefoot at home?', see online supplemental table 1), and scored their adherence to self-care from 0 (worst) to 7 (best). We obtained health-related quality of life on eight domains of the RAND 36-Item Short Form Health Survey (SF-36) (version 1.0) ${ }^{30}$ and the EuroQol visual analog scale (EQ VAS) ${ }^{31}$ SF-36 scores were recoded and combined and ranged from 0 (worst) to 100 (best). The EQ VAS score also ranged from 0 (worst imaginable health) to 100 (best imaginable health). We assessed the socioeconomic status (SES) per participant as per postal code, provided by the Netherlands Institute for Social Research (outcome ranges from -5 for lowest possible SES to +5 for highest possible SES).

There were no potential predictors that showed to be strongly correlated with each other (ie, correlation

\begin{tabular}{|c|c|c|}
\hline Potential predictor & Outcome & $\begin{array}{l}\text { Missing } \\
\text { values } \mathrm{n}(\%)\end{array}$ \\
\hline Age (years) & $64.6 \pm 10.5$ & \\
\hline Males & $220(72.4)$ & \\
\hline Body mass index $\left(\mathrm{kg} / \mathrm{m}^{2}\right)$ & $29.8 \pm 5.3$ & \\
\hline Caucasian & $283(93.1)$ & \\
\hline Type of diabetes & & $4(1.3)$ \\
\hline Type 1 & $66(21.7)$ & \\
\hline Type 2 & $234(77.0)$ & \\
\hline Years of diabetes & $20 \pm 14$ & $3(1.0)$ \\
\hline $\mathrm{HbA1c}(\%)$ & $7.7 \pm 3.6$ & $65(21.4)$ \\
\hline Retinopathy & $151(49.7)$ & $2(0.7)$ \\
\hline Nephropathy & $60(19.7)$ & $1(0.3)$ \\
\hline Dialysis & $4(1.3)$ & \\
\hline $\begin{array}{l}\text { Smoking or history of } \\
\text { smoking }\end{array}$ & $169(55.6)$ & \\
\hline Consumption of alcohol & $199(65.5)$ & \\
\hline Walking aid & $89(29.3)$ & \\
\hline Living alone & $105(34.5)$ & \\
\hline Level of education & & $2(0.7)$ \\
\hline Low & $117(38.5)$ & \\
\hline Medium & $96(31.6)$ & \\
\hline High & $89(29.3)$ & \\
\hline Employed & $75(24.7)$ & \\
\hline Custom-made footwear & $205(67.4)$ & $2(0.7)$ \\
\hline Walking barefoot at home & $113(37.2)$ & \\
\hline Adherence to self-care & $4.7 \pm 1.4$ & \\
\hline $\begin{array}{l}\text { At-home foot temperature } \\
\text { monitoring }\end{array}$ & $151(49.7)$ & \\
\hline \multicolumn{3}{|l|}{ Care center } \\
\hline University medical center & $88(28.9)$ & \\
\hline Community hospital & $134(44.1)$ & \\
\hline Podiatry practice & $82(27.0)$ & \\
\hline \multicolumn{3}{|l|}{ Peripheral neuropathy } \\
\hline Mild & $28(9.2)$ & \\
\hline Severe & $276(90.8)$ & \\
\hline \multicolumn{3}{|l|}{ Peripheral artery disease } \\
\hline Grade 1 & $197(64.8)$ & \\
\hline Grade 2 & $107(35.2)$ & \\
\hline \multicolumn{3}{|l|}{ Foot deformity } \\
\hline Absent & $17(5.6)$ & \\
\hline Mild & $58(19.1)$ & \\
\hline Moderate & $202(66.4)$ & \\
\hline Severe & $27(8.9)$ & \\
\hline \multicolumn{3}{|l|}{ History of amputation } \\
\hline Absent & $223(73.4)$ & \\
\hline Lesser toe(s) & $29(9.5)$ & \\
\hline Hallux or more proximal ${ }^{\star}$ & $52(17.1)$ & \\
\hline
\end{tabular}

Continued 


\begin{tabular}{|c|c|c|}
\hline Potential predictor & Outcome & $\begin{array}{l}\text { Missing } \\
\text { values } \mathrm{n}(\%)\end{array}$ \\
\hline Minor lesions at entry & $121(39.8)$ & $31(10.2)$ \\
\hline \multicolumn{2}{|c|}{ Plantar location of previously healed ulcer } & $1(0.3)$ \\
\hline Non-plantar† & $185(60.9)$ & \\
\hline Plantar & $118(38.8)$ & \\
\hline $\begin{array}{l}\text { Months since healing of } \\
\text { previous ulcer } \ddagger\end{array}$ & $7(2-15)$ & $1(0.3)$ \\
\hline $\begin{array}{l}\text { Months duration of last two } \\
\text { ulcers }\end{array}$ & $4(2-9)$ & $1(0.3)$ \\
\hline $\begin{array}{l}\text { 36-Item Short Form Health } \\
\text { Survey }\end{array}$ & & $13(4.3)$ \\
\hline Physical functioning & $59 \pm 22$ & \\
\hline Role functioning/physical & $50(0-100)$ & \\
\hline Role functioning/emotional & $100(33-100)$ & \\
\hline Energy/fatigue & $60 \pm 22$ & \\
\hline Emotional well-being & $78 \pm 18$ & \\
\hline Social functioning & $75(63-100)$ & \\
\hline Pain & $67 \pm 27$ & \\
\hline General health & $49 \pm 20$ & \\
\hline EuroQol visual analog scale & $69 \pm 15$ & $23(7.6)$ \\
\hline Social economic score & $-0.24 \pm 1.17$ & $3(1.0)$ \\
\hline
\end{tabular}

Data are expressed as number (\%), mean \pm SD or median [IQR]. *Seven participants had a unilateral transtibial or transfemoral amputation.

†Including nine participants who were included based on having a history of Charcot neuro-osteoarthropathy.

‡For participants included based only on having a history of

Charcot neuro-osteoarthropathy, 48 months was used.

coefficient $>0.5$ ) and therefore we considered all the above-mentioned potential predictors as variables in the model.

No variable had more than $25 \%$ of missing data (table 1). We used five multivariate imputations for all variables with missing values by applying the chained equations approach. ${ }^{32}$ This provided multiple imputations for multivariate missing data for any variable type, where each incomplete variable was imputed by a separate model (fully conditional specification method).

\section{Model development}

We developed two logistic regression models to predict foot ulcer recurrence: one for any ulcer recurrence (model 1), and one for plantar foot ulcer recurrence (model 2). We adhered to the Transparent Reporting of a Multivariable Prediction Model for Individual Prognosis or Diagnosis statement. ${ }^{33}$

We considered all potential predictors as variables for the models based on clinical reasoning, knowledge from peer-reviewed literature, and availability in everyday clinical practice.

\section{Model fitting and validation}

Model development was conformed to previous strategies, ${ }^{24}$ and went through four stages: (1) the creation of five data sets without missing values using multiple imputations; (2) selection of potential predictors selected in the majority of the imputed data sets; (3) fitting a logistic regression model on each of the five imputed data sets to predict ulcer outcome based on these variables; and (4) pooling the coefficients of the separate five models to obtain the final prediction model. The final logistic regression model was represented by its linear predictor. Predicted probabilities were calculated using the linear predictor in the formula: $1 /\left(1+e^{\text {-linear predictor }}\right)$.

In each imputation data set we used backward variable selection based on the Akaike information criterion (AIC) to find the optimal set of predictors. ${ }^{34}$ By giving a penalty for model complexity (in terms of the number of included variables), the AIC strikes a good balance between the likelihood of the model (which always increases with the number of included variables) and its complexity (the more complex the model, the more likely it overfits the data).

We used 10-fold cross-validation to internally validate our prediction model. This means that the entire model development strategy (including the five multiple imputation data sets and the variable selection process) was repeated in each of the 10 -folds on the training set $(90 \%$ of the data) and tested on the $10 \%$ held-out data set of that fold.

Because our RCT may show that at-home foot temperature monitoring reduces risk of ulcer recurrence, this intervention may predict outcome in one or both models. We therefore developed the model both including and excluding this intervention, as foot temperature monitoring is not yet standard of practice, and other predictors may enter the model if the intervention is not considered.

\section{Model performance}

We assessed model performance in terms of discrimination and calibration. ${ }^{35}$ Discrimination refers to the ability of a model to give a higher probability of the event (ie, ulcer recurrence) to those participants with the event than those without. We measured discrimination for the final prediction model by the area under the receiver operating characteristic curve (AUC) using the mean and two times the SD (2SD). ${ }^{36}$ The AUC ranges from 0 to 1 , with 1 representing perfect discrimination. Furthermore, we presented the AUC plots of the final models. Calibration refers to the closeness of the predicted values to the observed ones. We assessed the calibration using calibration graphs. The Brier Score, which combines both discrimination and calibration, was also assessed for all five pooled models and the final prediction model (mean, 2SD). The Brier Score is the mean squared error of a prediction and ranges from 0 to 1 , with 0 representing perfect concordance between predicted and observed values. ${ }^{37}$ 
We performed descriptive statistics using SPSS V.26.0 (SPSS) and all model analyses in the R statistical environment (R Foundation for Statistical Computing V4.0.2 for Windows (http://www.R-project.org)), ${ }^{38}$ with the mice V.3.11.0 and bootStepAIC V.1.2-0 packages (both available on https://cran.r-project.org/ at the time of publication).

\section{RESULTS}

Baseline participant characteristics are presented in table 1. Of a total 304 participants, 220 were male and the mean age was 64.6 years. Demographic data corresponded with previous studies. ${ }^{729}$ Foot ulcer recurrence in 18 months occurred in 126 participants $(41.4 \%)$, with a mean time to ulceration of 212 days (SD: 154, range 5-532). Plantar foot ulcer recurrence occurred in 70 participants $(23.0 \%)$, with a mean time to plantar ulceration of 206 days (SD: 159, range 15-532). During 18 months of follow-up there were no participants lost to follow-up, while eight participants died during follow-up. Table 2 provides the univariate analyses of all potential predictors with both outcomes.

\section{Model 1: ulcer recurrence at any foot site}

This model contained six predictors (table 3): a younger age, more severe peripheral sensory neuropathy, fewer months since healing of the previous ulcer, presence of a minor lesion, and the use of a walking aid were positive predictors for ulcer recurrence and at-home foot temperature monitoring was a negative predictor for ulcer recurrence. The linear predictor was: 0.284-0.0299*age in years $+1.57 *$ more severe peripheral sensory neuropathy $-0.0486 *$ months since last healed ulcer $+0.704 *$ minor lesion present $+0.800 *$ use of walking aid- $0.503 *$ use of at-home foot temperature monitoring. When model 1 was rerun excluding foot temperature monitoring as intervention, the model contained the same predictors (results not shown).

Based on the average predictions per participant of the final model in the five imputed data sets, the predicted probability of foot ulcer recurrence and the observed number of recurrent foot ulcers agreed over almost the whole range of probabilities (figure 1). When the predicted probability was $>0.70$ the model slightly underestimated the proportion of observed ulcers. The mean AUC of the model was 0.69 (2SD 0.040) (figure 2). The mean Brier Score was 0.22 (2SD 0.011).

\section{Model 2: plantar foot ulcer recurrence}

This model contained seven predictors (table 3 ): ayounger age, plantar location of the previous ulcer, fewer months since healing of the previous ulcer, presence of a minor lesion, use of a walking aid, consumption of alcohol and foot care received in a university medical center. The linear predictor was: $-0.129-0.0313 *$ age in years $+0.921 *$ plantar location of the previous ulcer-0.0379*months since last healed ulcer $+0.777 *$ minor lesion present $+0.828 *$ use of walking aid $+0.966 *$ consumption of alcohol- $(0.554 *$ foot care received in a community hospitall- $0.917 *$ foot care received in a podiatry practice). For this equation, foot care received in a university medical center was the reference category.

Based on the average predictions per participant of the final model in the five imputed data sets, the predicted probability of foot ulcer recurrence and the observed number of recurrent foot ulcers agreed over almost the whole range of probabilities (figure 1). The predicted probability underestimated the observed ulcer recurrences when around 0.30 and slightly overestimated when $>0.50$ (figure 1). The mean AUC of the model was 0.66 (2SD 0.023) (figure 2). The mean Brier Score was 0.16 (2SD 0.0048).

Table 4 provides the predicted probabilities including the $95 \%$ CIs for two characteristic persons with diabetes using synthesized data.

\section{DISCUSSION}

We used data from the largest two-arm trial on foot ulcer recurrence in diabetes to date, including a representative and demographically and disease-related diverse group of people all at high risk of diabetic foot ulceration (IWGDF risk 3) ${ }^{10}$ In this group we found six predictors of foot ulcer recurrence. These predictors are all easy to obtain in clinical practice, and together capable of predicting ulcer recurrence with good calibration and fair discrimination. We found seven predictors of plantar foot ulcer recurrence, also all easy-to-obtain variables, together predicting with reasonable calibration and fair discrimination. These prediction models can help in risk assessment and in reallocating resources for ulcer prevention treatment in this high-risk group of people with diabetes.

Four predictors were identified in both models: younger age, use of a walking aid, presence of a minor lesion, and fewer months since last healed ulcer. A younger age has previously also been associated with a higher risk of ulcer development. $^{2}{ }^{39-41}$ Use of a walking aid was not previously considered as potential predictor in studies and subsequently never associated with ulcer recurrence. Use of a walking aid may represent more disease severity (eg, neuropathy, peripheral artery disease, foot deformity) or more frailty, affecting one's ability to walk without additional support, and thus increasing risk of trauma and recurrence. Both of these variables are easy to obtain in clinical practice.

A minor lesion is a well-known risk factor of plantar foot ulcer recurrence, as previous studies have shown. ${ }^{1524}$ Our findings confirm these results and extend them to any foot ulcer recurrence. The presence of a minor lesion should therefore warn healthcare professionals that immediate treatment is needed, such as through callus removal or offloading the minor lesion, and that patients should be seen more frequently until the minor lesion has been resolved. ${ }^{13}{ }^{42}$ Fewer months since the last ulcer healed is likely a predictor because skin and underlying tissue are still regaining strength and remain vulnerable 
Table 2 Univariate analyses for potential predictors associated with outcome 1 (all recurrent foot ulcers) and outcome 2 (all recurrent plantar foot ulcers)

\begin{tabular}{|c|c|c|c|c|}
\hline \multirow[b]{2}{*}{ Potential predictor } & \multicolumn{2}{|c|}{ Ulcer recurrence at any foot site } & \multicolumn{2}{|c|}{ Plantar foot ulcer recurrence } \\
\hline & OR (95\% Cl) & $P$ value & OR (95\% Cl) & $P$ value \\
\hline Age (years) & 0.977 (0.956 to 0.999$)$ & 0.042 & $0.974(0.950$ to 0.998$)$ & 0.038 \\
\hline Body mass index $\left(\mathrm{kg} / \mathrm{m}^{2}\right)$ & $0.982(0.941$ to 1.026$)$ & 0.418 & 0.997 (0.948 to 1.049$)$ & 0.920 \\
\hline Caucasian & $1.064(0.434$ to 2.607$)$ & 0.892 & $0.774(0.252$ to 2.379$)$ & 0.654 \\
\hline Type 2 & $0.938(0.544$ to 1.620$)$ & 0.880 & $0.869(0.464$ to 1.629$)$ & 0.661 \\
\hline Years of diabetes & $1.001(0.985$ to 1.017$)$ & 0.923 & $0.999(0.980$ to 1.017$)$ & 0.881 \\
\hline $\mathrm{HbA1c}(\%)$ & 1.003 (0.989 to 1.017$)$ & 0.690 & $1.008(0.992$ to 1.025$)$ & 0.329 \\
\hline Retinopathy & $1.242(0.787$ to 1.962$)$ & 0.352 & 1.250 (0.732 to 2.136$)$ & 0.414 \\
\hline Consumption of alcohol & 1.315 (0.809 to 2.135$)$ & 0.269 & $1.879(1.024$ to 3.448$)$ & 0.042 \\
\hline Walking aid & 1.487 (0.903 to 2.447$)$ & 0.119 & 1.604 (0.912 to 2.820$)$ & 0.101 \\
\hline Living alone & $1.231(0.763$ to 1.986$)$ & 0.394 & 0.907 (0.515 to 1.598$)$ & 0.736 \\
\hline \multicolumn{5}{|l|}{ Level of education } \\
\hline Low & Reference & 0.163 & Reference & 0.516 \\
\hline Medium & 1.367 (0.787 to 2.374$)$ & 0.268 & 1.177 (0.612 to 2.262$)$ & 0.625 \\
\hline High & 1.714 (0.978 to 3.002$)$ & 0.060 & $1.462(0.765$ to 2.794$)$ & 0.251 \\
\hline Employed & 0.994 (0.585 to 1.687$)$ & 0.982 & 0.709 (0.369 to 1.364$)$ & 0.303 \\
\hline Custom-made footwear & 1.582 (0.958 to 2.612$)$ & 0.073 & 1.472 (0.808 to 2.684$)$ & 0.207 \\
\hline Community hospital & $0.729(0.424$ to 1.252$)$ & 0.252 & $0.592(0.322$ to 1.088$)$ & 0.091 \\
\hline Podiatry practice & $0.543(0.292$ to 1.008$)$ & 0.053 & 0.404 (0.192 to 0.849$)$ & 0.017 \\
\hline \multicolumn{5}{|l|}{ Peripheral neuropathy } \\
\hline Mild & Reference & & Reference & \\
\hline Severe & 6.699 (1.976 to 22.711$)$ & 0.002 & 4.250 (0.983 to 18.375$)$ & 0.053 \\
\hline \multicolumn{5}{|l|}{ Peripheral artery disease } \\
\hline Grade 1 & Reference & & Reference & \\
\hline Grade 2 & $1.103(0.685$ to 1.777$)$ & 0.687 & 0.803 (0.454 to 1.422$)$ & 0.452 \\
\hline \multicolumn{5}{|l|}{ Foot deformity } \\
\hline Absent & Reference & 0.060 & Reference & 0.113 \\
\hline Mild & 0.698 (0.221 to 2.204$)$ & 0.540 & 0.747 (0.175 to 3.193$)$ & 0.694 \\
\hline Moderate & $1.444(0.514$ to 4.056$)$ & 0.486 & $1.495(0.412$ to 5.417$)$ & 0.541 \\
\hline Severe & 2.292 (0.656 to 8.009$)$ & 0.194 & 2.745 (0.630 to 11.956$)$ & 0.179 \\
\hline \multicolumn{5}{|l|}{ History of amputation } \\
\hline Absent & Reference & 0.005 & Reference & 0.044 \\
\hline Lesser toe(s) & $1.424(0.652$ to 3.111$)$ & 0.375 & $1.032(0.397$ to 2.685$)$ & 0.949 \\
\hline
\end{tabular}

Continued 
Table 2 Continued

\begin{tabular}{|c|c|c|c|c|}
\hline \multirow[b]{2}{*}{ Potential predictor } & \multicolumn{2}{|c|}{ Ulcer recurrence at any foot site } & \multicolumn{2}{|c|}{ Plantar foot ulcer recurrence } \\
\hline & OR $(95 \% \mathrm{Cl})$ & $P$ value & OR $(95 \% \mathrm{Cl})$ & $P$ value \\
\hline Hallux or more proximal & 2.805 (1.506 to 5.223$)$ & 0.001 & 2.277 (1.186 to 4.373$)$ & 0.013 \\
\hline Minor lesions at entry & 3.066 (1.908 to 4.925$)$ & 0.001 & 2.659 (1.532 to 4.616$)$ & 0.001 \\
\hline \multicolumn{5}{|c|}{ Plantar location of previously healed ulcer } \\
\hline Non-plantar & Reference & & Reference & \\
\hline Plantar & 1.497 (0.938 to 2.389$)$ & 0.091 & 2.667 (1.545 to 4.603$)$ & 0.001 \\
\hline $\begin{array}{l}\text { Months since healing of previous } \\
\text { ulcer }\end{array}$ & 0.949 (0.926 to 0.973$)$ & 0.001 & 0.951 (0.921 to 0.983$)$ & 0.003 \\
\hline Months duration of last two ulcers & 1.025 (0.999 to 1.051$)$ & 0.059 & 1.024 (0.998 to 1.052$)$ & 0.072 \\
\hline \multicolumn{5}{|l|}{ SF-36 Short Form Health Survey } \\
\hline Physical functioning & 0.997 (0.989 to 1.005$)$ & 0.464 & 0.997 (0.988 to 1.007$)$ & 0.595 \\
\hline Role functioning/physical & $1.000(0.995$ to 1.005$)$ & 0.982 & $1.001(0.995$ to 1.007$)$ & 0.720 \\
\hline Role functioning/emotional & 0.998 (0.992 to 1.003$)$ & 0.406 & 1.003 (0.996 to 1.010$)$ & 0.415 \\
\hline Energy/fatigue & 0.997 (0.986 to 1.007$)$ & 0.549 & 0.998 (0.986 to 1.011$)$ & 0.806 \\
\hline Emotional well-being & 0.993 (0.980 to 1.006$)$ & 0.284 & $1.001(0.986$ to 1.016$)$ & 0.874 \\
\hline Social functioning & 0.995 (0.985 to 1.004$)$ & 0.270 & $1.000(0.989$ to 1.011$)$ & 0.958 \\
\hline Pain & $1.000(0.991$ to 1.008$)$ & 0.991 & 0.998 (0.989 to 1.008$)$ & 0.766 \\
\hline General health & 0.994 (0.983 to 1.005$)$ & 0.294 & $1.004(0.991$ to 1.018$)$ & 0.531 \\
\hline EuroQol visual analog scale & 0.999 (0.984 to 1.014$)$ & 0.898 & 1.007 (0.990 to 1.025$)$ & 0.417 \\
\hline Social economic score & $1.044(0.857$ to 1.272$)$ & 0.670 & $0.986(0.784$ to 1.241$)$ & 0.903 \\
\hline
\end{tabular}

for breakdown in the first months after epithelization. Our models confirm earlier reports of a higher risk when time since last ulcer healed is shorter. ${ }^{6}$ This suggests that extra attention to offloading and more frequent foot care should be given in the first months after healing.

Peripheral sensory neuropathy and at-home monitoring foot temperature were specific predictors for ulcer recurrence at any foot site. Peripheral sensory neuropathy has been studied extensively in ulcer risk estimation in populations with and without ulcer history. ${ }^{23} 4344$ Few studies found it to be associated with ulcer recurrence, ${ }^{20}{ }^{40}$ presumably because most high-risk people have neuropathy, limiting its differential effect in risk analyses. However, peripheral sensory neuropathy advances progressively, ${ }^{45}{ }^{46}$ where inability to perceive vibration from a tuning fork is a sign of an earlier stage of neuropathy, while inability to perceive pressure of a monofilament is a later stage sign. ${ }^{45}$ This may explain our finding that more severe peripheral sensory neuropathy (ie, lack of perception of both the vibration from the tuning fork and pressure from the monofilament) predicted ulcer recurrence (in comparison to only not sensing the vibration from the tuning fork).

These prediction models were based on data from an RCT explaining that the intervention of at-home monitoring of foot temperature was one of the potential predictors and turned out to be a predictor of ulcer recurrence in the study. Despite evidence from two metaanalyses, ${ }^{47} 48$ and recommendations for its use included in international guidelines, ${ }^{13}$ at-home monitoring of foot temperatures is not standard in clinical practice. We therefore ran the prediction model with and without this intervention and found the same predictors of ulcer recurrence regardless of its inclusion, indicating that these predictors are important, independent of this intervention, in foot ulcer recurrence.

Specific predictors for ulcer recurrence on the plantar foot were a plantar location of the previous ulcer, consumption of alcohol and foot care received in a university medical center. The first may be understandable from the more biomechanical etiology of plantar versus non-plantar foot ulcers, with plantar ulcers more likely to recur at the same site. ${ }^{6}{ }^{15}$ Increased attention to offloading these high-risk plantar areas is needed. ${ }^{2942}$ Only one previous study associated more alcohol consumption with ulcer recurrence. ${ }^{19}$ While moderate use of alcohol is acceptable in people with diabetes, a potential explanation could be the effect of alcohol on a person's health in general and specifically on blood glucose regulation, which may in turn increase ulcer risk. ${ }^{49}$ Unfortunately, detailed information on the use of alcohol was not available in our study, and more research on this association is needed.

Foot care in a university medical center represents tertiary foot care as proposed in the IWGDF guidelines, and is therefore probably a marker for more disease severity. ${ }^{10}$ Furthermore, since it is only a predictor for plantar foot ulcer recurrence, it most likely reflects the more advanced biomechanical burden in these people treated in tertiary care. This larger burden might be 
Table 3 Predictors for model 1 (all recurrent foot ulcers) and model 2 (all recurrent plantar foot ulcers)

\begin{tabular}{|c|c|c|}
\hline Predictor & Coefficient & $95 \% \mathrm{Cl}$ \\
\hline \multicolumn{3}{|l|}{ Model 1} \\
\hline Intercept & 0.284 & -0.163 to 2.20 \\
\hline Age & -0.0299 & -0.0541 to -0.00570 \\
\hline $\begin{array}{l}\text { Severity of } \\
\text { peripheral sensory } \\
\text { neuropathy }\end{array}$ & 1.57 & 0.327 to 2.82 \\
\hline $\begin{array}{l}\text { Months since } \\
\text { healing of previous } \\
\text { ulcer }\end{array}$ & -0.0486 & -0.0757 to -0.0215 \\
\hline Minor lesions & 0.704 & 0.170 to 1.24 \\
\hline Walking aid & 0.800 & 0.225 to 1.37 \\
\hline $\begin{array}{l}\text { At-home foot } \\
\text { temperature } \\
\text { monitoring }\end{array}$ & -0.503 & -1.01 to 0.000222 \\
\hline \multicolumn{3}{|l|}{ Model 2} \\
\hline Intercept & -0.129 & -2.07 to 1.81 \\
\hline Age & -0.0313 & -0.0608 to -0.00191 \\
\hline $\begin{array}{l}\text { Plantar location of } \\
\text { previous ulcer }\end{array}$ & 0.921 & 0.313 to 1.53 \\
\hline $\begin{array}{l}\text { Months since } \\
\text { healing of previous } \\
\text { ulcer }\end{array}$ & -0.0379 & -0.0721 to -0.00370 \\
\hline Minor lesions & 0.777 & 0.140 to 1.41 \\
\hline Walking aid & 0.828 & 0.179 to 1.48 \\
\hline $\begin{array}{l}\text { Alcohol } \\
\text { consumption }\end{array}$ & 0.966 & 0.274 to 1.66 \\
\hline \multicolumn{3}{|l|}{ Care center } \\
\hline \multicolumn{3}{|c|}{$\begin{array}{l}\text { University medical Reference } \\
\text { center }\end{array}$} \\
\hline $\begin{array}{l}\text { Community } \\
\text { hospital }\end{array}$ & -0.564 & -1.23 to 0104 \\
\hline Podiatry practice & -0.917 & -1.74 to -0.0941 \\
\hline
\end{tabular}

Model 1

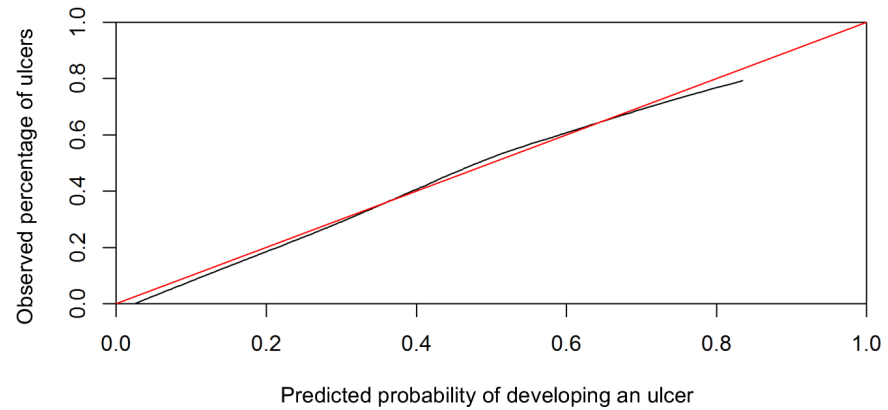

explained by the wider availability of biomechanical assessment tools in university medical centers and subsequent referral from secondary to tertiary care of patients requiring such assessment.

Because data were obtained from a large multicenter trial in diabetic foot disease, our prediction models are limited to high-risk people with diabetes that match the inclusion criteria for the trial. While external validation is needed to determine generalizability of the models, the only trial-specific criteria concerned excluding participants with bilateral amputation proximal to the Lisfranc joint and expected survival $<18$ months. Future external validation may show differences in the performance due to potential selection bias in our trial compared with the situation were a prospective observational cohort analysis would have been conducted. Furthermore, with 126 and 70 ulcer events in the first and second models, respectively, we were limited by the number of predictors to select for the final model to avoid overfitting. Despite considering multiple potential predictors, our models had only fair discriminating performance. To increase performance, one likely needs to include more complex behavioral (eg, therapy adherence, ${ }^{29}$ stride count measures ${ }^{152450}$ ), social-economic, ${ }^{51}$ or biomechanical (eg, barefoot or in-shoe plantar pressures $^{1524}$ ) variables. However, that would jeopardize clinical utility as these variables are hard to obtain in everyday clinical practice. Another limitation is the interobserver variability in assessing some foot-related parameters by different investigators, such as foot deformity, peripheral sensory neuropathy, peripheral artery disease and minor lesions. To improve on the latter, two independent observers assessed the photographs of the feet for presence of foot deformity and minor lesions and they reached consensus on the outcome.

All predictors found can be easily obtained by healthcare professionals when screening people at high risk, and thus the prediction models can be

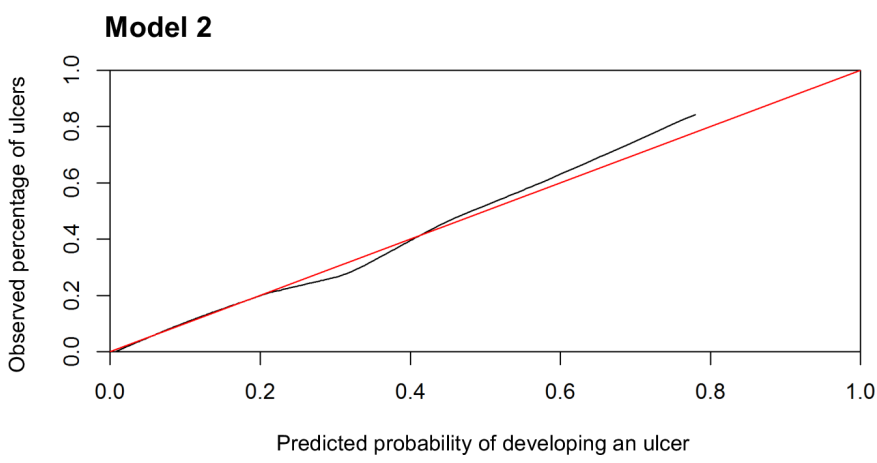

Figure 1 Calibration graphs for model 1 (all recurrent foot ulcers) and model 2 (all recurrent plantar foot ulcers). In each graph, the black lines show the observed proportion of the event versus the probability of the event as predicted by the model. Ideally, all the points fall on the diagonal red line. 
Model 1

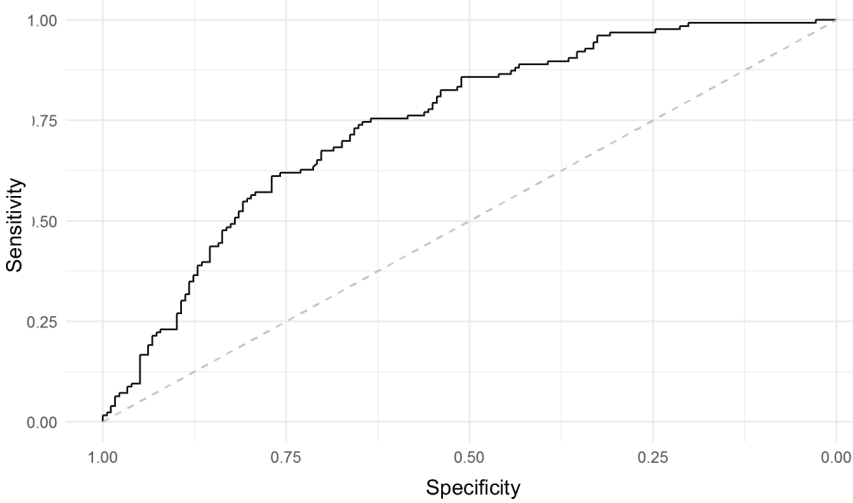

Model 2

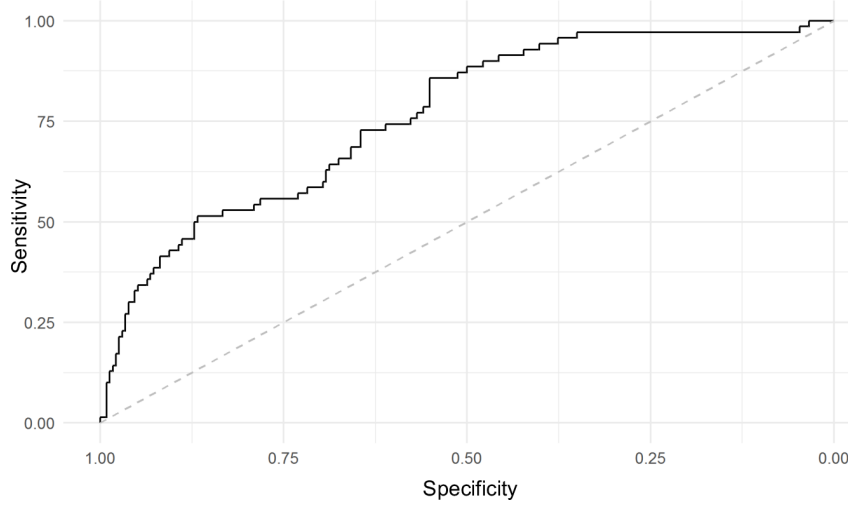

Figure 2 Area under the receiver operating characteristic curve (AUC) for model 1 (all recurrent foot ulcers) and model 2 (all recurrent plantar foot ulcers).

readily applied in everyday clinical practice. Using the linear predictor from both models, a healthcare provider can determine someone's risk of ulcer recurrence. When doing so, it is important to know that predictors should not be interpreted individually,

Table 4 The predicted probability of ulcer recurrence within 18 months using model 1 (all recurrent foot ulcers) and model 2 (all recurrent plantar foot ulcers) for two characteristic persons with diabetes using synthesized data

\begin{tabular}{|c|c|c|}
\hline & Person A & Person B \\
\hline \multicolumn{3}{|l|}{ Model 1} \\
\hline Age (years) & 50 & 80 \\
\hline $\begin{array}{l}\text { Severity of peripheral } \\
\text { sensory neuropathy }\end{array}$ & Severe & Mild \\
\hline $\begin{array}{l}\text { Months since healing of } \\
\text { previous ulcer }\end{array}$ & 3 & 24 \\
\hline Minor lesions & Yes & No \\
\hline Walking aid & No & Yes \\
\hline $\begin{array}{l}\text { At-home foot } \\
\text { temperature monitoring }\end{array}$ & Yes & No \\
\hline $\begin{array}{l}\text { Probability of ulcer } \\
\text { recurrence }(95 \% \mathrm{Cl})\end{array}$ & 0.60 (0.54 to 0.66$)$ & 0.08 (0.04 to 0.13$)$ \\
\hline \multicolumn{3}{|l|}{ Model 2} \\
\hline Age (years) & 50 & 80 \\
\hline $\begin{array}{l}\text { Plantar location of } \\
\text { previous ulcer }\end{array}$ & Yes & No \\
\hline $\begin{array}{l}\text { Months since healing of } \\
\text { previous ulcer }\end{array}$ & 3 & 24 \\
\hline Minor lesions & Yes & No \\
\hline Walking aid & No & Yes \\
\hline Alcohol consumption & No & Yes \\
\hline \multicolumn{3}{|l|}{ Care center } \\
\hline $\begin{array}{l}\text { University medical } \\
\text { center }\end{array}$ & $\begin{array}{l}\text { University medical } \\
\text { center }\end{array}$ & \\
\hline \multicolumn{3}{|l|}{ Community hospital } \\
\hline Podiatry practice & & Podiatry practice \\
\hline $\begin{array}{l}\text { Probability of ulcer } \\
\text { recurrence }(95 \% \mathrm{Cl})\end{array}$ & 0.47 (0.38 to 0.56$)$ & 0.06 (0.04 to 0.10$)$ \\
\hline
\end{tabular}

but only as a combination of variables that together may determine the risk of ulceration. To illustrate the potential use of the prediction models in clinical practice, we used synthesized data of two characteristic persons with diabetes and estimated the probability for ulcer recurrence (table 4). Person A has a high probability of developing a recurrent ulcer within 18 months, while person $\mathrm{B}$ has a low probability of developing a recurrent ulcer within 18 months. The combination of non-modifiable and modifiable predictors may help healthcare providers to better determine the frequency of foot screening and care, while the modifiable predictors (ie, minor lesions, use of at-home foot temperature monitoring, alcohol use) may suggest potential preventative treatment that aims to mitigate the risk for recurrence. Because of the high risk of ulcer recurrence, person A might, for example, be monitored carefully and treated for minor lesions. However, we emphasize that to understand the effect on ulcer recurrence risk of interventions targeting these modifiable predictors, adequately powered trials or etiological analyses are needed. On a more macroscopic level, our prediction models may help national health authorities and healthcare insurance companies in health policy so to better allocate the limited resources for foot care for people with diabetes who are at risk of foot ulceration.

\section{CONCLUSION}

These internally validated prediction models contain easy-to-obtain modifiable and non-modifiable variables and are built from a representative and diverse group of people with diabetes, neuropathy and foot ulcer history. These models better stratify people at high risk of foot ulceration and help determine who should be monitored more carefully and treated more intensively with the aim to improve on the prevention of foot ulcer recurrence in people with diabetes.

Contributors $\mathrm{SAB}$ conceived and designed the original trial from which the data were used. WBAdS, AAH and SAB conceived the plan for this study. WBAdS, JJvN 
and SAB collected the data. MCS, AAH and WBAdS ran the prediction models and performed the statistical analysis. WBAdS wrote the manuscript. MCS, AAH, JJvN, JGvB and SAB critically reviewed and edited the manuscript. All authors read and approved the final manuscript.

Funding The DIATEMP trial was funded by the Netherlands Organization for Health Research and Development (ZonMw, project number 837002508), with 10\% matching funded by the Dutch Society for Podiatrists (NVvP) and Dutch Branch Organization for Pedicures (ProVoet)

Disclaimer The funders had no influence on study design, data collection, management, analysis, and interpretation, the writing of the report, or the decision to submit for publication, and had no authority over any of these activities.

Competing interests None declared.

Patient consent for publication Not required.

Ethics approval This study was approved by the research ethics committees of all seven participating centers (approval ID 2015_105 from the ethics committee of the main study site, Amsterdam UMC-Location AMC). We obtained written informed consent prior to inclusion from all participants.

Provenance and peer review Not commissioned; externally peer reviewed.

Data availability statement Data are available upon reasonable request.

Supplemental material This content has been supplied by the author(s). It has not been vetted by BMJ Publishing Group Limited (BMJ) and may not have been peer-reviewed. Any opinions or recommendations discussed are solely those of the author(s) and are not endorsed by BMJ. BMJ disclaims all liability and responsibility arising from any reliance placed on the content. Where the content includes any translated material, BMJ does not warrant the accuracy and reliability of the translations (including but not limited to local regulations, clinical guidelines, terminology, drug names and drug dosages), and is not responsible for any error and/or omissions arising from translation and adaptation or otherwise.

Open access This is an open access article distributed in accordance with the Creative Commons Attribution Non Commercial (CC BY-NC 4.0) license, which permits others to distribute, remix, adapt, build upon this work non-commercially, and license their derivative works on different terms, provided the original work is properly cited, appropriate credit is given, any changes made indicated, and the use is non-commercial. See: http://creativecommons.org/licenses/by-nc/4.0/.

\section{ORCID iDs}

Wouter B aan de Stegge http://orcid.org/0000-0003-4834-1691

Jaap J van Netten http://orcid.org/0000-0002-6420-6046

Sicco A Bus http://orcid.org/0000-0002-8357-9163

\section{REFERENCES}

1 Boulton AJM, Vileikyte L, Ragnarson-Tennvall G, et al. The global burden of diabetic foot disease. Lancet 2005;366:1719-24.

2 Gonzalez JS, Vileikyte L, Ulbrecht JS, et al. Depression predicts first but not recurrent diabetic foot ulcers. Diabetologia 2010;53:2241-8.

3 Kerr M, Barron E, Chadwick P, et al. The cost of diabetic foot ulcers and amputations to the National health service in England. Diabet Med 2019;36:995-1002

4 Crawford F, McCowan C, Dimitrov BD, et al. The risk of foot ulceration in people with diabetes screened in community settings: findings from a cohort study. QJM 2011;104:403-10.

5 Zhang Y, Lazzarini PA, McPhail SM, et al. Global disability burdens of diabetes-related lower-extremity complications in 1990 and 2016. Diabetes Care 2020;43:964-74.

6 Armstrong DG, Boulton AJM, Bus SA. Diabetic foot ulcers and their recurrence. N Engl J Med 2017;376:2367-75.

7 Prompers L, Huijberts M, Apelqvist J, et al. High prevalence of ischaemia, infection and serious comorbidity in patients with diabetic foot disease in Europe. baseline results from the Eurodiale study. Diabetologia 2007;50:18-25.

8 National Institute for Health and Care Excellence (NICE). NG19 diabetic foot problems: prevention and management. London: National Institute for Health and Care Excellence: Clinical Guidelines, 2015.

9 American Diabetes Association. 11. Microvascular Complications and Foot Care: Standards of Medical Care in Diabetes-2020. Diabetes Care 2020;43:S135-51.
10 Schaper NC, van Netten JJ, Apelqvist J, et al. Practical guidelines on the prevention and management of diabetic foot disease (IWGDF 2019 update). Diabetes Metab Res Rev 2020;36 Suppl 1:e3266.

11 Monteiro-Soares M, Boyko EJ, Ribeiro J, et al. Risk stratification systems for diabetic foot ulcers: a systematic review. Diabetologia 2011;54:1190-9.

12 Monteiro-Soares M, Ribas R, Pereira da Silva C, et al. Diabetic foot ulcer development risk classifications' validation: a multicentre prospective cohort study. Diabetes Res Clin Pract 2017;127:105-14.

13 Bus SA, Lavery LA, Monteiro-Soares M, et al. Guidelines on the prevention of foot ulcers in persons with diabetes (IWGDF 2019 update). Diabetes Metab Res Rev 2020;36 Suppl 1:e3269.

14 Peters EJG, Armstrong DG, Lavery LA. Risk factors for recurrent diabetic foot ulcers: site matters. Diabetes Care 2007;30:2077-9.

15 Waaijman R, de Haart M, Arts MLJ, et al. Risk factors for plantar foot ulcer recurrence in neuropathic diabetic patients. Diabetes Care 2014;37:1697-705.

16 Crawford F, Cezard G, Chappell FM, et al. A systematic review and individual patient data meta-analysis of prognostic factors for foot ulceration in people with diabetes: the International research collaboration for the prediction of diabetic foot ulcerations (PODUS). Health Technol Assess 2015;19:1-210.

17 Bus SA, van Netten JJ. A shift in priority in diabetic foot care and research: $75 \%$ of foot ulcers are preventable. Diabetes Metab Res Rev 2016;32 Suppl 1:195-200.

18 Van Netten JJ, Woodburn J, Bus SA. The future for diabetic foot ulcer prevention: a paradigm shift from stratified healthcare towards personalized medicine. Diabetes Metab Res Rev 2019;36:e3234.

19 Connor H, Mahdi OZ. Repetitive ulceration in neuropathic patients. Diabetes Metab Res Rev 2004;20 Suppl 1:S23-8.

20 Monami M, Longo R, Desideri CM, et al. The diabetic person beyond a foot ulcer: healing, recurrence, and depressive symptoms. J Am Podiatr Med Assoc 2008:98:130-6.

21 Dubský M, Jirkovská A, Bem R, et al. Risk factors for recurrence of diabetic foot ulcers: prospective follow-up analysis in the Eurodiale subgroup. Int Wound J 2013;10:555-61.

22 Moons KGM, Royston P, Vergouwe Y. Prognosis and prognostic research: what, why, and how? BMJ 2008;388:b375

23 Crawford F, Cezard G, Chappell FM, et al. The development and validation of a multivariable prognostic model to predict foot ulceration in diabetes using a systematic review and individual patient data meta-analyses. Diabet Med 2018;35:1480-93.

24 Aan de Stegge WB, Abu-Hanna A, Bus SA. Development of a multivariable prediction model for plantar foot ulcer recurrence in high-risk people with diabetes. BMJ Open Diabetes Res Care 2020;8:e001207.

25 Aan de Stegge WB, Mejaiti N, van Netten JJ, et al. The costeffectiveness and cost-utility of at-home infrared temperature monitoring in reducing the incidence of foot ulcer recurrence in patients with diabetes (DIATEMP): study protocol for a randomized controlled trial. Trials 2018;19:520.

26 Rogers LC, Frykberg RG, Armstrong DG, et al. The Charcot foot in diabetes. Diabetes Care 2011;34:2123-9.

27 Van Netten JJ, Bus SA, Apelqvist J. Definitions and criteria for diabetic foot disease. Diabetes Metab Res Rev 2019;36:e3286.

28 Schaper NC. Diabetic foot ulcer classification system for research purposes: a progress report on criteria for including patients in research studies. Diabetes Metab Res Rev 2004;20 Suppl 1:S90-5.

29 Bus SA, Waaijman R, Arts ML. Effect of custom-made footwear on foot ulcer recurrence in diabetes. Diabetes Care 2013;36:4109-16.

30 Hays RD, Sherbourne CD, Mazel RM. The Rand 36-Item health survey 1.0. Health Econ 1993:2:217-27.

31 Rabin R, de Charro F. EQ-5D: a measure of health status from the EuroQol group. Ann Med 2001;33:337-43.

32 Van Buuren S, Groothuis-Oudshoorn K. Mice: multivariate imputation by chaned equations in R. J Stat Softw 2011;45:1-67.

33 Collins GS, Reitsma JB, Altman DG, et al. Transparent reporting of a multivariable prediction model for individual prognosis or diagnosis (TRIPOD): the TRIPOD statement. Br J Surg 2015;102:148-58.

34 Akaike $\mathrm{H}$. Information theory as an extension of the maximum likelihood principle. In: Petrov BN, Csaki F, eds. Second International Sympposium on information theory. Budapest: Akademiai Kiado, 1973: 267-81.

35 Harrell FE, Lee KL, Mark DB. Multivariable prognostic models: issues in developing models, evaluating assumptions and adequacy, and measuring and reducing errors. Stat Med 1996;15:361-87.

36 Hanley JA, McNeil BJ. The meaning and use of the area under a receiver operating characteristic $(\mathrm{ROC})$ curve. Radiology 1982;143:29-36.

37 Brier GW. Verification of forecasts expressed in terms of probability. Mon Weather Rev 1950;78:1-3. 
38 R-Core-Team. A language and environment for statistical computing. Vienna, Austria: R Foundation for Statistical Computing, 2019. https://www.r-project.org/

39 Armstrong DG, Holtz-Neiderer K, Wendel C, et al. Skin temperature monitoring reduces the risk for diabetic foot ulceration in high-risk patients. Am J Med 2007;120:1042-6.

40 Monteiro-Soares M, Boyko EJ, Ribeiro J, et al. Predictive factors for diabetic foot ulceration: a systematic review. Diabetes Metab Res Rev 2012;28:574-600.

41 Hicks CW, Canner JK, Mathioudakis N, et al. Incidence and risk factors associated with ulcer recurrence among patients with diabetic foot ulcers treated in a multidisciplinary setting. J Surg Res 2020;246:243-50.

42 Bus SA, Armstrong DG, Gooday C, et al. Guidelines on offloading foot ulcers in persons with diabetes (IWGDF 2019 update). Diabetes Metab Res Rev 2020;36 Suppl 1:e3274.

43 Young MJ, Breddy JL, Veves A, et al. The prediction of diabetic neuropathic foot ulceration using vibration perception thresholds. A prospective study. Diabetes Care 1994;17:557-60.

44 Abbott CA, Vileikyte L, Williamson S, et al. Multicenter study of the incidence of and predictive risk factors for diabetic neuropathic foot ulceration. Diabetes Care 1998;21:1071-5.

45 Rinkel WD, Aziz MH, Van Neck JW, et al. Development of grading scales of pedal sensory loss using Mokken scale analysis on the
Rotterdam diabetic foot study test battery data. Muscle Nerve 2019;60:520-7.

46 Rinkel WD, Rizopoulos D, Aziz MH, et al. Grading the loss of sensation in diabetic patients: a psychometric evaluation of the Rotterdam diabetic foot study test battery. Muscle Nerve 2018;58:559-65.

47 Alahakoon C, Fernando M, Galappaththy C, et al. Meta-Analyses of randomized controlled trials reporting the effect of home foot temperature monitoring, patient education or offloading footwear on the incidence of diabetes-related foot ulcers. Diabet Med 2020;37:1266-79.

48 Crawford F, Nicolson DJ, Amanna AE, et al. Preventing foot ulceration in diabetes: systematic review and meta-analyses of RCT data. Diabetologia 2020;63:49-64.

49 Ley SH, Hamdy O, Mohan V, et al. Prevention and management of type 2 diabetes: dietary components and nutritional strategies. Lancet 2014;383:1999-2007.

50 Armstrong DG, Lavery LA, Holtz-Neiderer K, et al. Variability in activity may precede diabetic foot ulceration. Diabetes Care 2004;27:1980-4.

51 Hurst JE, Barn R, Gibson L, et al. Geospatial mapping and data linkage uncovers variability in outcomes of foot disease according to multiple deprivation: a population cohort study of people with diabetes. Diabetologia 2020;63:659-67. 